\title{
Neoadjuvant rituximab modulates the tumor immune environment in patients with high risk prostate cancer
}

Stephen T. Ryan ${ }^{1}$, Jing Zhang ${ }^{3}$, Danielle N. Burner ${ }^{1}$, Michael Liss ${ }^{7}$, Emily Pittman³ ${ }^{3}$ Michelle Muldong ${ }^{1}$, Ahmed Shabaik ${ }^{2}$, Jason Woo ${ }^{1}$, Nicole Basler ${ }^{1}$, Jonathan Cunha', Shabnam Shalapour ${ }^{3}$, Monica V. Estrada ${ }^{8}$, Michael Karin ${ }^{3,4}$, Karen Messer ${ }^{3,6}$, Stephen Howell ${ }^{3,5}$, Christopher J. Kane ${ }^{1,3}$ and Christina A. M. Jamieson ${ }^{1,3^{*}}$ (D)

\begin{abstract}
Background: Immunotherapeutic regulation of the tumor microenvironment in prostate cancer patients is not understood. Most antibody immunotherapies have not succeeded in prostate cancer. We showed previously that high-risk PCa patients have a higher density of tumor infiltrating B-cells in prostatectomy specimens. In mouse models, anti-CD20 antibody ablation of B-cells delayed PCa regrowth post-treatment. We sought to determine whether neoadjuvant anti-CD20 immunotherapy with rituximab could reduce CD20+B cell infiltration of prostate tumors in patients.

Methods: An open label, single arm clinical trial enrolled eight high-risk PCa patients to receive one cycle of neoadjuvant rituximab prior to prostatectomy. Eleven clinical specimens with similar characteristics were selected as controls. Treated and control samples were concurrently stained for CD20 and digitally scanned in a blinded fashion. A new method of digital image quantification of lymphocytes was applied to prostatectomy sections of treated and control cases. CD20 density was quantified by a deconvolution algorithm in pathologist-marked tumor and adjacent regions. Statistical significance was assessed by one sided Welch's t-test, at 0.05 level using a gatekeeper strategy. Secondary outcomes included CD3+ T-cell and PD-L1 densities.
\end{abstract}

Results: Mean CD20 density in the tumor regions of the treated group was significantly lower than the control group $(p=0.02)$. Mean CD3 density in the tumors was significantly decreased in the treated group $(p=0.01) . C D 20, C D 3$ and PD-L1 staining primarily occurred in tertiary lymphoid structures (TLS). Neoadjuvant rituximab was well-tolerated and decreased B-cell and T-cell density within high-risk PCa tumors compared to controls.

Conclusions: This is the first study to treat patients prior to surgical prostate removal with an immunotherapy that targets B-cells. Rituximab treatment reduced tumor infiltrating B and T-cell density especially in TLSs, thus, demonstrating inter-dependence between B- and T-cells in prostate cancer and that Rituximab can modify the immune environment in prostate tumors. Future studies will determine who may benefit from using rituximab to improve their immune response against prostate cancer.

\footnotetext{
*Correspondence: camjamieson@health.ucsd.edu

${ }^{1}$ Department of Urology, UCSD Moores Cancer Center, University

of California San Diego School of Medicine, 3855 Health Sciences Drive,

Mail Code: 0987, La Jolla, CA 92093-0987, USA

Full list of author information is available at the end of the article
}

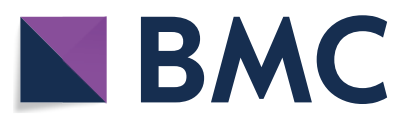

(c) The Author(s) 2020. This article is licensed under a Creative Commons Attribution 4.0 International License, which permits use, sharing, adaptation, distribution and reproduction in any medium or format, as long as you give appropriate credit to the original author(s) and the source, provide a link to the Creative Commons licence, and indicate if changes were made. The images or other third party material in this article are included in the article's Creative Commons licence, unless indicated otherwise in a credit line to the material. If material is not included in the article's Creative Commons licence and your intended use is not permitted by statutory regulation or exceeds the permitted use, you will need to obtain permission directly from the copyright holder. To view a copy of this licence, visit http://creativeco mmons.org/licenses/by/4.0/. The Creative Commons Public Domain Dedication waiver (http://creativecommons.org/publicdomain/ zero/1.0/) applies to the data made available in this article, unless otherwise stated in a credit line to the data. 
Trial registration NCT01804712, March 5th, 2013 https://clinicaltrials.gov/ct2/show/NCT01804712?cond=NCT0180471 $2 \&$ draw $=2 \&$ rank $=1$

Keywords: Prostate cancer, Rituximab, Immunotherapy, CD20, CD3, PD-L1, Neoadjuvant, Prostatectomy, Tumor infiltrating lymphocytes (TILs)

\section{Background}

The tumor microenvironment plays a role in cancer cell proliferation, immune evasion, metastasis, and treatment resistance which is mediated by direct cancer cell contact and/or indirect cell signaling through cytokines, chemokines, and growth factors [1, 2]. Successful targeting of T-cell immune checkpoint pathways has shown dramatic responses in this environment for multiple malignancies but has failed as a monotherapy in prostate cancer (PCa) [3-9]. This may be due to the unique nature of the $\mathrm{PCa}$ tumor immune microenvironment [10]. In PCa mouse models, the presence of an immunosuppressive B-cell subpopulation was associated with accelerated recurrence of castrate resistant PCa [11] and suppressed the cytotoxic T-cell response normally associated with chemotherapy [12]. In prostatectomy specimens, we have demonstrated previously that high B-cell density is associated with biochemical failure in high-risk patients $[11,13]$. While inhibition of B-cells may provide an alternative therapeutic approach, no clinical trials have attempted to modulate B-cells in the tumor microenvironment.

Rituximab is a well-tolerated monoclonal antibody against the CD20 antigen which is highly expressed on most B-cells. Rituximab was originally approved by the FDA for the treatment of Non-Hodgkin's Lymphoma, with expanded indications to many non-malignant B-cell related diseases. In a PCa mouse model, anti-CD20 treatment decreased the number of tumor infiltrating B-cells and delayed the onset of castrate resistant disease [11]. We sought to determine whether neoadjuvant treatment of high-risk PCa patients with the anti-CD20 immunotherapy, Rituximab, could reduce $\mathrm{B}$-cell infiltration of $\mathrm{PCa}$ tumors.

Men with high-risk PCa were prospectively enrolled to undergo a single 1-month cycle of neoadjuvant rituximab prior to curative intent prostatectomy (NCT01804712). The primary objective was to determine the histological response of tumor infiltrating B-cells. Secondary objectives included assessing the impact on oncological outcomes, serum PSA response, immunohistochemical staining profiles of other immune cells, and observe patient safety and tolerability.

\section{Methods}

\section{Study design and data sources}

Study population

After IRB approval, we conducted an open-label nonrandomized single arm study of neoadjuvant rituximab in patients with high-risk $\mathrm{PCa}$ who were candidates for radical prostatectomy ("PROTUX" NCT01804712). Eight patients were enrolled who presented to a single tertiary care institution and prostatectomies were performed by a high-volume surgeon. High-risk was defined as either Kattan nomogram probability of 5-year disease free status $<60 \%$ or a Gleason score $\geq 8$ [14]. Inclusion criteria were the ability to understand and provide consent, candidate for curative intent prostatectomy, Eastern Cooperative Oncology Group (ECOG) performance status 0-1, adequate organ function within 21 days of study entry based on routine screening hematologic and biochemical laboratory values. Exclusion criteria included prior treatment for prostatic adenocarcinoma (excluding transurethral resection of prostate), evidence of metastatic disease on cross sectional imaging or bone scan, history of chronic infection (especially hepatitis B or C, or HIV), positive hepatitis $B$ or $C$ serology, concurrent or past use of investigational agents within 1 month of study entry and use of erectile dysfunction medication within 14 days of entry.

\section{Study treatment}

Enrolled patients received rituximab $375 \mathrm{mg} / \mathrm{m}^{2}$ intravenously once weekly for 4 treatments over 28 days. Patients were pre-medicated with diphenhydramine $25 \mathrm{mg}$ intravenously and acetaminophen $650 \mathrm{mg}$ orally. To reduce the risk of infusion reaction, the initial rate was $50 \mathrm{mg} / \mathrm{h}$ and was increased by $50 \mathrm{mg} / \mathrm{h}$ increments every $30 \mathrm{~min}$ if there was no reaction $(\max =400 \mathrm{mg} / \mathrm{h})$. Protocol guidelines allowed for dose modification for minor reactions and discontinued infusion for severe reactions. Vital signs were recorded before and after each treatment, laboratory tests were performed at each treatment, along with any medication changes. Prostatectomy was performed within 14 days of last treatment with planned lymph node dissection. Follow-up was conducted for 3 years as standard of care. PSA measurements occurred every 3 months for the first 2 years and every 6 months for the third year. Adverse events were assessed at each 
study visit for the duration of study and for 28 days after the discontinuation of rituximab.

\section{Procedures \\ Tissue procurement}

Whole-mount resected prostate tissue was processed according to standard institutional procedures. Routine histological assessment for tumor staging was performed and then excess tissue was made available for research purposes. The control group consisted of archived radical prostatectomy specimens stored in a clinical pathology lab, selected for similar pathologic characteristics. Slides were prepared in blinded fashion from eight treated prostatectomies (two slides from one multifocal specimen) and 11 controls. Samples were labeled with the subject's de-identified study number and collection date, and all of the following processing was performed concurrently.

\section{Immunohistochemistry}

Formalin fixed, paraffin embedded prostatectomy tissue blocks with the highest percentage of tumor were selected by clinical urologic pathologist (AS) and $4 \mu \mathrm{m}$ thick serial sections were labeled with anonymized slide labels for blinded immunohistochemical staining and analysis. First and last serial sections were stained with hematoxylin and eosin and pathology was confirmed by the pathologist. Staining was performed as previously described with minor modifications [13]. Immunohistochemical staining was performed by the UCSD Moores Cancer Center Tissue Technology Shared Resources manually for anti-CD20, catalog \# MO755 (Agilent Dako) then on IntelliPath (Biocare Medical) Autostainer using anti-CD3 catalog \# CME324A (Biocare Medical) and anti-PD-L1 catalog \#13684S (Cell Signaling), HRP polymers from Biocare Medical, RHRP520 L and RT517 L labeled Envision anti-mouse DAKO catalog \# K4000 and $\mathrm{DAB}$ substrate. The ChromPure Rabbit IgG catalog \# 011-000-003 (Jackson Laboratories) isotype control antibody was used to determine background staining threshold. Tumor regions on stained slides were marked by a blinded pathologist (AS).

\section{Histological response/digital microscope image scanning}

All slides were digitally scanned at $40 \times$ magnification at Tissue Technology Shared Resources using the Aperio AT2 system (Leica BioSystems), the background illumination levels were calibrated using an automated prescan procedure. The acquired digital images representing whole tissue sections were evaluated for image quality and rescanned if needed. Slide images were viewed and analyzed using ImageScope viewer. Immunohistochemical staining was quantified by computer algorithm in tumor and adjacent tissue regions using an Aperio ${ }^{\mathrm{TM}}$
Digital Pathology Slide Scanner as previously described [13]. The Spectrum Analysis algorithm package and ImageScope analysis software were applied to quantify IHC staining. The algorithm used was the "color deconvolution" (version 9; Aperio Technologies, Inc.). Color deconvolution algorithm was applied to each stained section, tested on negative and positive control slides and tuned on specimen slides. Positive staining thresholds for low, intermediate and high intensity staining and threshold for background staining were set using anti-CD20, antiCD3 or anti-PD-L1 on positive control human spleen sections and isotype-matched negative control antibody stained sections.

\section{Histological response/digital microscope image analysis}

ImageScope pen tool was used to outline the pathologist's marked tumor region on each digital slide image and analysis was performed using color deconvolution algorithm as previously described [13]. The negative pen tool was used to exclude artifacts within an analysis area (ex: folds, tears, large clear areas devoid of tissue, and non-cellular precipitates of concentrated stain). The stained area $\left(\mathrm{mm}^{2}\right)$ and total area $\left(\mathrm{mm}^{2}\right)$ were calculated within the tumor region. The same was performed for all specimen on the slide (tumor plus normal adjacent tissue regions) and normal adjacent tissue areas were determined by simple subtraction (All specimen-tumor region). The ratio of total stained area over total area $\left(\mathrm{mm}^{2} / \mathrm{mm}^{2}\right)$ was determined for both tumor region and normal adjacent tissue.

\section{Statistical analysis \\ Study design and outcomes}

The original primary endpoint was the rate of histologic response, defined as having B-cell density within the tumor below a pre-determined threshold (18th percentile), comparing to concurrently assayed control samples. Using a Simon's two stage design at 5\% significance with $80 \%$ power to detect a response rate of $50 \%$ or more against a null hypothesis of $20 \%$ response, the original sample size was estimated to include 18 treated and 27 controls specimens. However, the trial was closed due to low accrual after 8 treated subjects, and the primary endpoint was revised prior to analysis. Study personnel were blinded during the outcome assessment. The dual primary hypotheses were (1) mean CD20 density in tumor would be less in treated specimens compared to controls; and (2) the mean within-patient difference, tumor minus adjacent non-neoplastic tissue, would be less in treated compared to control specimens. Primary hypotheses were tested at overall $5 \%$ level using a one-sided Welch's t-test, using a gatekeeper strategy to correct for the 2 comparisons. Secondary endpoints included CD3 and 
PDL-1 density, biochemical recurrence, change in serum PSA, serum leukocyte count, and adverse event rates.

\section{Results}

Eight men were enrolled and treated with neoadjuvant rituximab and compared to 11 controls. Mean age of the treatment and control patients was $62.3( \pm 5.2)$ and $63.4( \pm 6.4)$ years, respectively. Both groups were mostly Caucasian $(87.5 \%$ and $90.9 \%)$ and non-Hispanic (75\% and $81.8 \%)$. PSA at diagnosis was $7.7( \pm 4.7)$ and $7.5( \pm 4.7) \mathrm{ng} / \mathrm{mL}$ for the treated and control groups,

Table 1 Demographics

\begin{tabular}{|c|c|c|}
\hline & Rituximab $(n=8)$ & $\begin{array}{l}\text { Controls } \\
(n=11)\end{array}$ \\
\hline Age (mean/SD) & $62.3(5.2)$ & $63.4(6.4)$ \\
\hline \multicolumn{3}{|l|}{ Race (\%) } \\
\hline White & $7(87.5)$ & $10(90.9)$ \\
\hline Unknown & $1(12.5)$ & $1(9.1)$ \\
\hline \multicolumn{3}{|l|}{ Ethnicity (\%) } \\
\hline Hispanic & $1(12.5)$ & $1(9.1)$ \\
\hline Non-hispanic & $6(75)$ & $9(81.8)$ \\
\hline Unknown & $1(12.5)$ & $1(9.1)$ \\
\hline PSA at diagnosis (mean/SD) & $7.7(4.7)$ & $7.5(4.7)$ \\
\hline \multicolumn{3}{|l|}{$\begin{array}{l}\text { Gleason risk group after pros- } \\
\text { tatectomy }(\mathrm{n} / \%)\end{array}$} \\
\hline I (GS $3+3)$ & - & $3(27.3)^{\mathrm{a}}$ \\
\hline II (GS $3+4)$ & $1(12.5)$ & - \\
\hline III (GS 4+3) & $2(25)$ & - \\
\hline IV and $V(G S \geq 8)$ & $5(62.5)$ & $8(72.7)$ \\
\hline \multicolumn{3}{|l|}{ pT stage } \\
\hline pT2a-c & $3(37.5)$ & $2(18.2)$ \\
\hline pT3a-b & $5(62.5)$ & $9(81.8)$ \\
\hline
\end{tabular}

${ }^{a}$ All were pT3a respectively. The pathologic stage of treated specimens were $37.5 \%$ pT2a-c and $62.5 \%$ pT3a-b, with Gleason Grade risk groups II $(\mathrm{n}=1,12.5 \%)$, III $(\mathrm{n}=2,25 \%)$, and IV\&V $(\mathrm{n}=5,62.5 \%)$. The control prostatectomies consisted of $18.2 \%$ pT2a-c and $81.8 \%$ pT3a-b, and Gleason Grade risk groups I $(\mathrm{n}=3,27.3 \%)$, and IV and V $(\mathrm{n}=8$, $72.7 \%$ ). Note, all Gleason risk group I (GS $3+3$ ) prostatectomies in the control group were pT3a. Descriptive characteristics are listed in Table 1.

\section{Primary outcomes}

Immunohistochemical analysis of the B-cell marker, CD20, was performed on radical prostatectomy tissue as shown in Fig. 1. Immunohistochemical staining of serial prostatectomy sections showed the presence of CD20+ B-cells cells aggregated in immune cell foci known as tertiary lymphoid structures (TLS). B-cell density within the tumor region of the rituximab treated samples was $0.027 \mathrm{~mm}^{2} / \mathrm{mm}^{2}$ (95\% CI 0.021 , 0.033 ) and $0.044 \mathrm{~mm}^{2} / \mathrm{mm}^{2}$ (95\% CI $\left.0.028,0.062\right)$ in the controls (Fig. 2a). A significant difference in B-cell density was detected $(\mathrm{p}=0.02)$ (Table 2). The non-neoplastic adjacent tissue had a B-cell density of $0.032 \mathrm{~mm}^{2} / \mathrm{mm}^{2}$ in the treated prostatectomies and $0.036 \mathrm{~mm}^{2} / \mathrm{mm}^{2}$ in the control specimens, with no difference observed ( $p=0.36$ ) (Fig. 2a, Table 2). The mean within group CD20+ difference (tumor - non-neoplastic adjacent densities) was $-0.005 \mathrm{~mm}^{2} / \mathrm{mm}^{2}(95 \%$ CI $-0.028,0.017)$ in the treated and $0.009 \mathrm{~mm}^{2} / \mathrm{mm}^{2}$ $(95 \% \mathrm{CI}-0.004,0.023)$ in the control groups, suggesting a greater overall CD20+ decrease in the treated tissue, however, it did not reach, statistical significance $(\mathrm{p}=0.11)$ (Fig. 2b, Table 2). All p-values from one-sided Welch's t-tests.

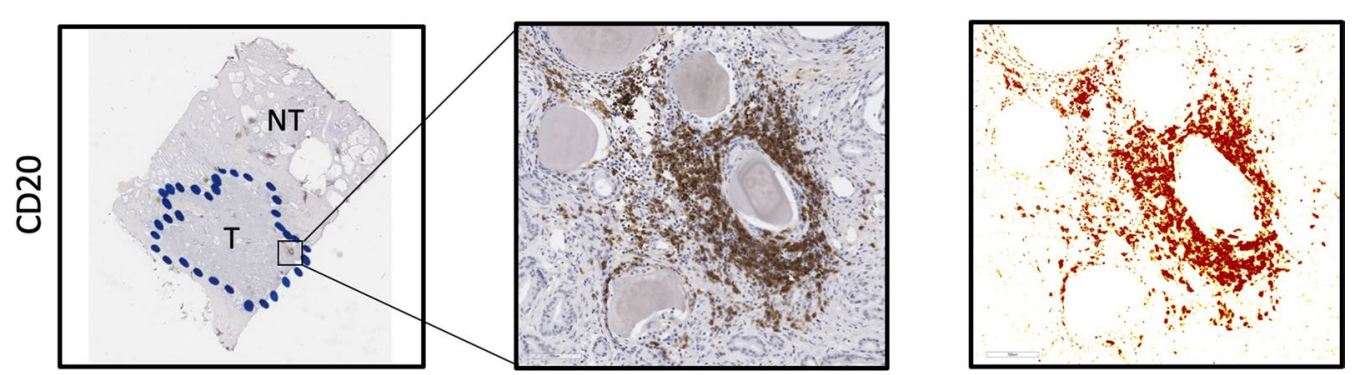

Fig. 1 Immunohistochemical staining of serial prostatectomy sections showed presence of CD20+ B-cells cells aggregated in immune cell foci known as tertiary lymphoid structures (TLSs). a Representative AperioScope scanned image of anti-CD20 stained prostatectomy section counter-stained with hematoxylin. Tumor regions outlined by pathologist markings in blue, $T=$ tumor, NT=non-tumor, $\times 10$ magnification. $\mathbf{b}$ Box inset enlarged at $\times 200$ magnification shows CD20+ B-cells stained brown in bright-field. c Post-deconvolution image of CD20 staining. After Imagescope deconvolution algorithm is run the stained color intensity is represented as image pixels with high intensity (brown), intermediate (orange) and low (yellow) staining intensity 


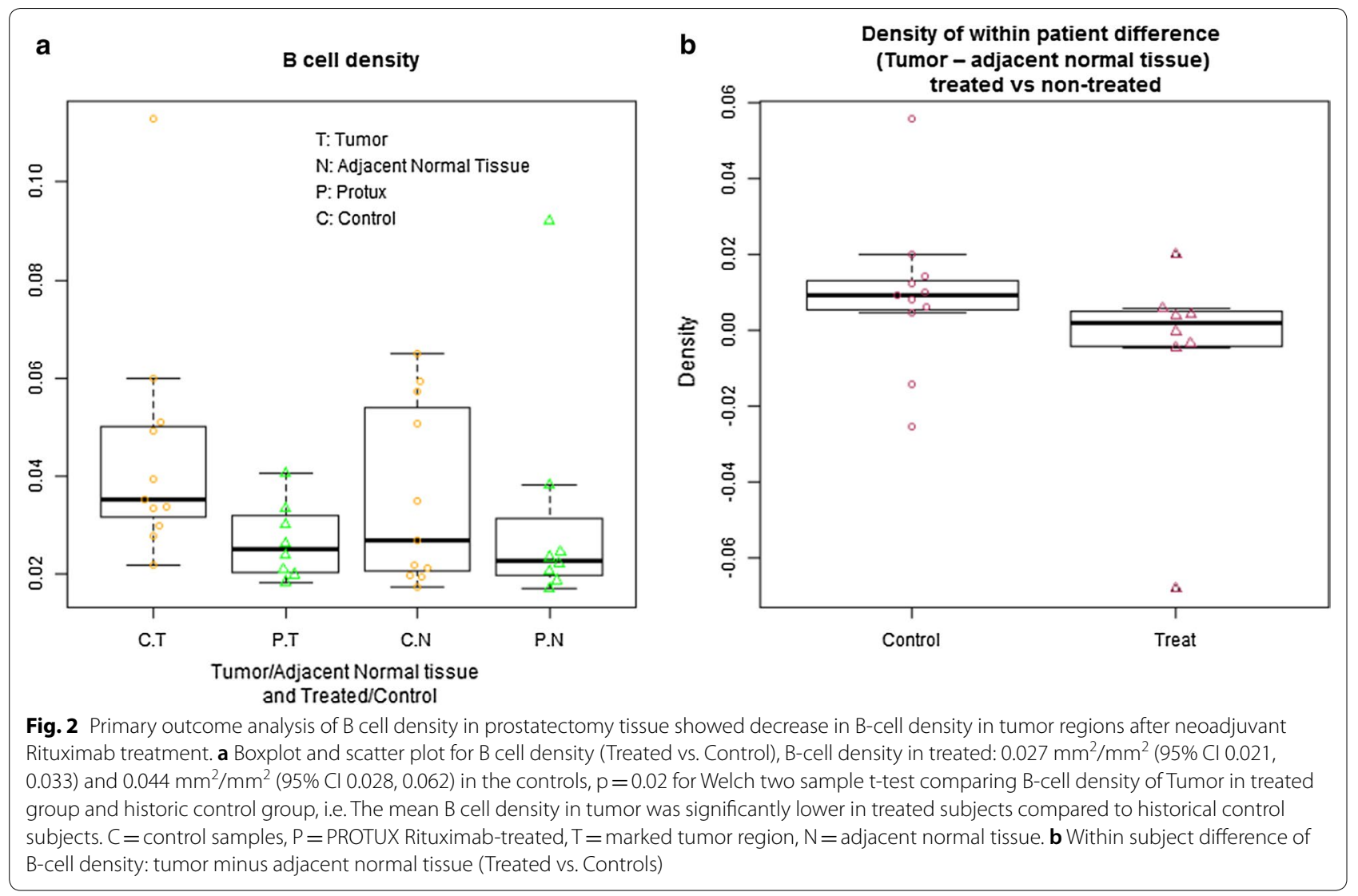

Table 2 Primary analysis: results

\begin{tabular}{lccc}
\hline B-cell density $\left(\mathbf{m m}^{\mathbf{2}} / \mathbf{m m}^{2}\right)$ & $\begin{array}{l}\text { Rituximab } \\
\text { Mean }(\mathbf{9 5 \%} \mathrm{Cl})\end{array}$ & $\begin{array}{l}\text { Controls } \\
\text { Mean }(\mathbf{9 5 \%} \mathrm{Cl})\end{array}$ & $\boldsymbol{p}$ \\
\hline Tumor region & $0.027(0.021,0.033)$ & $0.044(0.028,0.062)$ & 0.02 \\
Non-neoplastic region & $0.032(0.011,0.053)$ & $0.036(0.023,0.048)$ & 0.36 \\
Within group difference & & $0.009(-0.004,+0.023)$ & 0.11 \\
Tumor - non-neoplastic & $-0.005(-0.028,+0.017)$ & & \\
\hline
\end{tabular}

Mean B-cell densities ( $95 \% \mathrm{Cl}$ ). (Top) B cell density within the Tumor and Normal tissue regions. (Bottom) Comparison of within group difference

1. Density of Tumor for subjects treated with Rituximab

2. Density of adjacent normal tissue for subjects treated with Rituximab

3. Use one sample t test to get the mean and $95 \% \mathrm{Cl}$. p value is from two sample t-test

For two sample t-test, the Welch (or Satterthwaite) approximation to the degrees of freedom is used

\section{Secondary outcomes}

Absolute lymphocyte count decreased by -0.29 [1000/ $\left.\mathrm{mm}^{3}\right]$ (95\% CI - 0.7, 0.12). No patients experienced leukopenia or thrombocytopenia throughout the study period. Serum PSA did not change appreciably over the course of neoadjuvant rituximab (Day1: $8.1 \mathrm{ng} / \mathrm{mL}(95 \%$ CI 4.26, 11.94), Day 29: $8.36 \mathrm{ng} / \mathrm{mL}$ (95\% CI 4.00, 12.72), $\mathrm{p}=0.84$, Wilcoxon signed rank test) (Table 3 and Fig. 3). For the 14 patients with 6-month follow-up, 2 patients in the control group and 1 patient in the treated group had a persistently elevated PSA. Four patients in the control group did not have 6-month follow-up; three were lost to follow-up, and the other died of unrelated causes. One patient in the treated group was lost to follow-up.

Immunohistochemical staining of serial prostatectomy sections showed the presence of $\mathrm{CD} 20+\mathrm{B}$-cells, $\mathrm{CD} 3+\mathrm{T}$-cells and PD-L+cells aggregated in immune cell foci known as tertiary lymphoid structures (TLS) 


\begin{tabular}{|c|c|c|}
\hline Patient study ID & Early PSA & Day 29 PSA \\
\hline 1 & 15.08 & 12.14 \\
\hline 2 & 14.5 & 16.52 \\
\hline 3 & 3.98 & 4.4 \\
\hline 4 & 5.98 & 5.96 \\
\hline 5 & 4.32 & 2.7 \\
\hline 6 & 10.52 & 14.43 \\
\hline 7 & 5.26 & 4.61 \\
\hline 8 & 5.16 & 6.09 \\
\hline
\end{tabular}

To determine the effectiveness of neoadjuvant rituximab in the treatment of prostate cancer as evaluated by the serum PSA

Wilcoxon signed rank test, $\mathrm{p}$-value $=0.84$

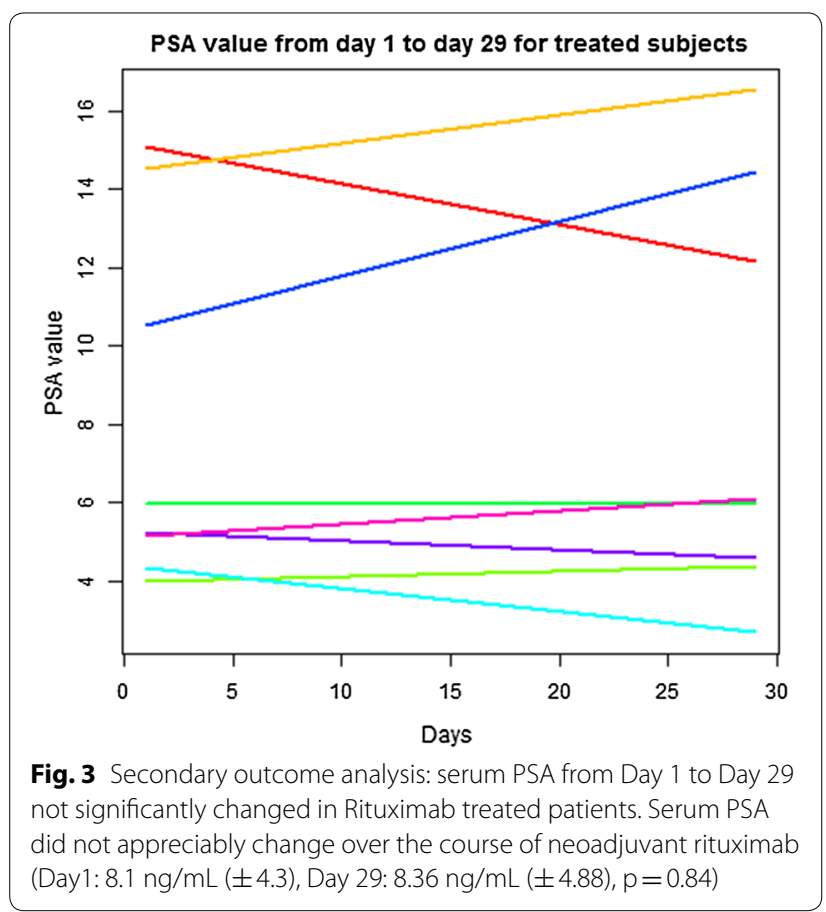

in tumor and non-tumor regions (Additional file 1: Figures S1, S2). Density was calculated for the pan T-cell marker, CD3, and the immune checkpoint marker, PD-L1 (Fig. 1). The mean CD3+T-cell density in the tumor region of the rituximab-treated group was $0.022 \mathrm{~mm}^{2}$ / $\mathrm{mm}^{2}$ (95\% CI $\left.0.012,0.033\right)$ and $0.042 \mathrm{~mm}^{2} / \mathrm{mm}^{2}$ (95\% CI $0.031,0.053)$ in the control group. A significant decrease in $\mathrm{CD} 3+\mathrm{T}$ cell density was detected $(\mathrm{p}=0.01)$ (Fig. $4 \mathrm{a}$, Table 4). The mean within group CD3+difference (tumor - normal adjacent densities) was $0.004 \mathrm{~mm}^{2} / \mathrm{mm}^{2}(95 \%$ CI $-0.005,0.013$ ) in the treated and (tumor - normal adjacent densities) was $0.021 \mathrm{~mm}^{2} / \mathrm{mm}^{2}$ (95\% CI 0.011 ,
0.031) in the control groups, suggesting a greater overall CD3 + decrease in the treated tissue which did reach statistical significance $(\mathrm{p}=0.01)$ (Fig. 4b, Table 4). All p-values except serum PSA from two-sided Welch's t-tests.

A non-significant decrease in the mean PD-L1 density $\left(\mathrm{mm}^{2} / \mathrm{mm}^{2}\right)$ in the treated (0.059) versus control samples (0.083) was observed $(p=0.36)$ (Table 5, Fig. 5a). The mean within group PD-L1+ difference (tumor - normal adjacent densities) was $0.005 \mathrm{~mm}^{2} / \mathrm{mm}^{2}$ (95\% CI $(-0.012,0.022)$ in the treated and $-0.049 \mathrm{~mm}^{2} / \mathrm{mm}^{2}$ (95\% CI $-0.248,0.151)$ in the control groups, suggesting a greater overall $\mathrm{PD}-\mathrm{L} 1+$ decrease in the treated tissue; however, it did not reach statistical significance $(\mathrm{p}=0.56)$ (Fig. 5b, Table 5).

\section{Adverse event}

All enrolled patients were able to complete rituximab treatment. Four patients experienced a total of 10 adverse events, 9/10 were Grade 1 and 2, with 4 of those 9 being possible or probably related to rituximab. There was only one event considered severe, a grade 4 thromboembolic event which occurred after surgery, deemed unrelated to rituximab. The patient was treated with anticoagulation without incident. No adverse events were definitively related to rituximab. Two patients experienced an infusion related reaction (Grade 2) after the initial dose. Both resolved and tolerated dose escalation per protocol. Results are listed in Table 6.

\section{Discussion}

Immunoregulation of the tumor microenvironment in human prostate cancer is not well understood $[1,2,15]$. In the present study, we demonstrated that neoadjuvant rituximab significantly decreased B-cell density within tumors compared to concurrently assayed controls $(\mathrm{p}=0.02)$ and appeared to reduce the density of tumor resident $\mathrm{B}$-cells to levels comparable to adjacent nonneoplastic tissue, $(\mathrm{p}=0.11$ relative to controls). There was also a significant decrease in CD3+ T-cell density within the tumor regions demonstrating the inter-dependence between $\mathrm{B}$ and T-cells in prostate cancer. Neoadjuvant rituximab was well tolerated with no attributable serious adverse events. Therefore, these results provide evidence that rituximab is a safe modifier of the immune environment within prostate tumors.

Lymphocyte infiltration plays a central role in cancer cell apoptosis and has been linked to tumor stage and recurrence free survival $[2,10,14,16]$. Observational studies of B-cell density in $\mathrm{PCa}$ have had conflicting results, with some reporting lower B-cells counts [17], while others described higher B-cell density only in highgrade tumors [18]. The prognostic implications of B-cell density in PCa are also mixed. Petitprez and co-workers 


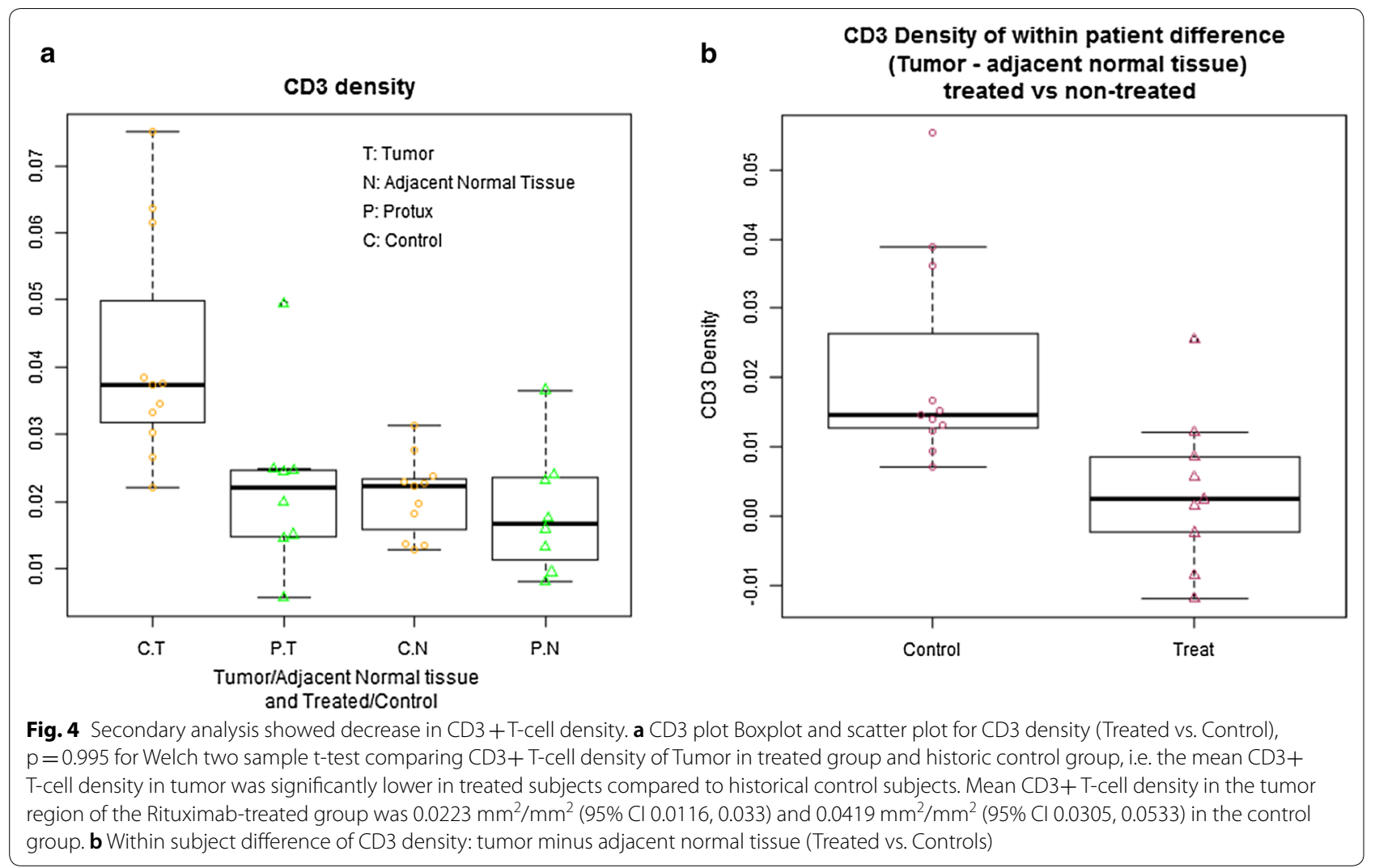

Table 4 Secondary analysis: CD3, a pan T-cell marker

\begin{tabular}{|c|c|c|c|}
\hline CD3+ density $\left(\mathrm{mm}^{2} / \mathrm{mm}^{2}\right)$ & $\begin{array}{l}\text { Rituximab } \\
\text { Mean }(95 \% \mathrm{Cl})\end{array}$ & $\begin{array}{l}\text { Controls } \\
\text { Mean }(95 \% \mathrm{Cl})\end{array}$ & $p$ \\
\hline Tumor region & $0.022(0.012,0.033)$ & $0.042(0.031,0.053)$ & 0.01 \\
\hline Non-neoplastic region & $0.019(0.011,0.026)$ & $0.021(0.017,0.025)$ & 0.56 \\
\hline \multicolumn{4}{|l|}{ Within group difference } \\
\hline Tumor - non-neoplastic & $0.004(-0.005,+0.013)$ & $0.021(+0.011,+0.031)$ & 0.01 \\
\hline
\end{tabular}

1. Density of tumor for subjects treated with Rituximab

2. Density of adjacent normal tissue for subjects treated with Rituximab

3. Use one sample $t$ test to get the mean and $95 \% \mathrm{Cl}$

4. $p$ value is from two sample $t$-test

For two sample t-test, the Welch (or Satterthwaite) approximation to the degrees of freedom is used

Null hypothesis is no difference. Alternative hypothesis is true difference in means is greater than 0

5. (Tumor - Normal) is calculated by: column D - column E

[19] showed recently that a high density of CD8+ cells plus PD-L1+ cells was associated with higher risk of biochemical recurrence in lymph node-positive patients, but no association was found with CD20+ cells.

Our prior work has shown increased tumor infiltrating CD20+B-cells were correlated with biochemical recurrence [13], while others remark that $B$-cells have no association with biochemical recurrence [20,21]. All studies agree that $\mathrm{B}$-cells are rare in $\mathrm{PCa}$ tumors, making the variations in results likely due to differences in analysis methods and lymphocyte quantification. To our knowledge this is the first trial to prospectively modulate B-cell density within $\mathrm{PCa}$ tumors. Pre-clinical work in $\mathrm{PCa}$ mouse models demonstrated a B-cell driven pathway that promoted castration resistance [11, 12]. Furthermore, decreased or depleted B-cell numbers within the tumor 
Table 5 Secondary analysis: PD-L1

\begin{tabular}{llcr}
\hline PD-L1 density $\left(\mathbf{m m}^{\mathbf{2}} / \mathbf{m m}^{\mathbf{2}}\right)$ & $\begin{array}{l}\text { Rituximab } \\
\text { Mean }(\mathbf{9 5 \%} \mathrm{Cl})\end{array}$ & $\begin{array}{l}\text { Controls } \\
\text { Mean }(\mathbf{9 5 \%} \mathbf{C l})\end{array}$ & $\boldsymbol{p}$ \\
\hline Tumor region & $0.059(0.018,0.099)$ & $0.083(0.040,0.127)$ & 0.36 \\
Non-neoplastic region & $0.054(0.004,0.103)$ & $0.132(0.056,0.321)$ & 0.39 \\
Within group difference & & $-0.049(-0.248,+0.151)$ & 0.56 \\
Tumor - non-neoplastic & $0.005(-0.012,+0.022)$ & & \\
\hline
\end{tabular}

1. Density of tumor for subjects treated with rituximab

2. Density of adjacent normal tissue for subjects treated with rituximab

3. Use one sample t test to get the mean and $95 \% \mathrm{Cl}$

4. $p$ value is from two sample $t$-test

For two sample t-test, the Welch (or Satterthwaite) approximation to the degrees of freedom is used

Null hypothesis is no difference

5. (Tumor - normal) is calculated by: column $\mathrm{K}$ - column L

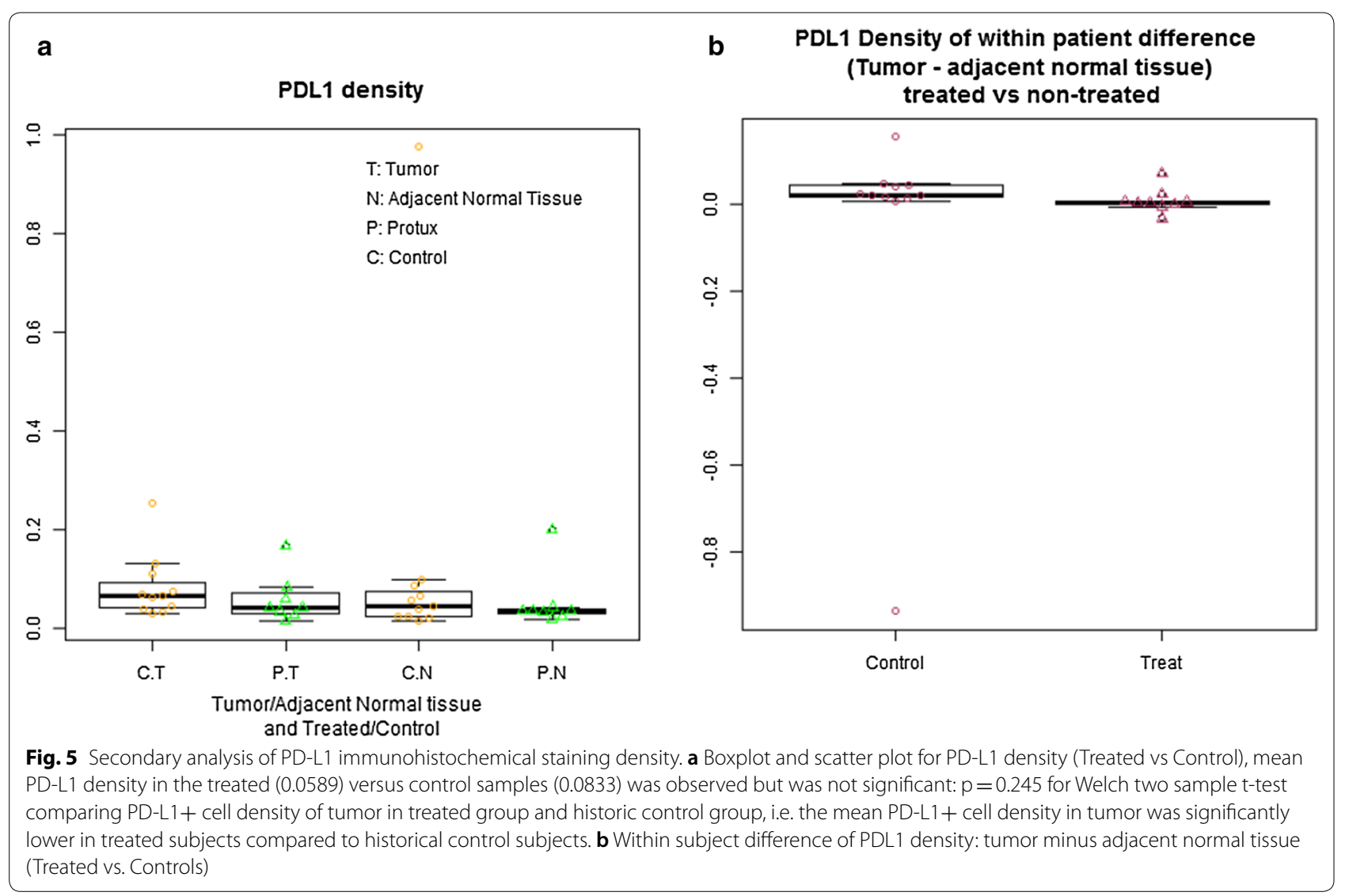

were associated with inhibited tumor growth and delay of metastasis. The current study was a successful phase I translation of the mouse model, whereby rituximab was able to decrease B-cell density in the PCa tumor.

The majority of immunotherapies are based on augmenting CD8+ cytotoxic T-cells (CTL), which normally assist in eradicating tumor cells but can become quiescent over time [22, 23]. Observational studies of PCa found that rare spontaneous regressions were associated with the lack of CD4+ T-regulatory cells while progression was associated with increased $\mathrm{CD} 4+\mathrm{T}$-regulatory cells, with no significant differences in CD4+ T-helper or CD8+T-cytotoxic concentrations [24, 25]. In animal models of advanced PCa, B-cell interactions were responsible for down-regulating T-cell dependent cytotoxicity, while B-cell depletion had no effect on the 
Table 6 Secondary analysis 4: safety and tolerability of neo-adjuvant rituximab

\begin{tabular}{llll}
\hline Severity/grade & Adverse events $(\mathbf{n})$ & $\begin{array}{l}\text { Possible, probable, or definite } \\
\text { attribution }(\mathbf{n})\end{array}$ & $\begin{array}{l}\text { Description of related adverse } \\
\text { events (n of patients affected) }\end{array}$ \\
\hline Mild/1 & 6 & 2 & Fatigue $(\times 2)$ \\
Moderate/2 & 3 & 2 & Infusion related reaction $(\times 2)$ \\
Severe/3 & 0 & 0 & \\
Life-threatening/4 & 1 & 0 & \\
Fatal/5 & 0 & 0 & \\
Total & 10 & 4 & \\
\hline
\end{tabular}

Adverse events (description, timing, grade [CTCAE v4.03], severity, seriousness, and relatedness)

number of CD4+ Treg cells within the tumor [12]. Following this result, we expected decreasing B-cells would have no effect on the number of T-cells in the treatment arm, and thus the decreased CD3+density, a pan T-cell marker, came as a surprise. To verify our finding, all samples were re-analyzed by three blinded researchers, with the CD3+density staying within $5 \%$ of the original findings. In different patient populations, rituximab has shown a range of $\mathrm{T}$ cell responses from no change in T-cell concentration [24], to an increase in all T-cell subpopulations [26], or dramatic decrease in CD4+ Treg cells [27]. These studies highlight that enumerating lymphocytes is often not sufficiently informative about functional immune interactions. The clinical implications of our findings are as yet unknown, as PCa emergence may be related to unique inhibitory pathways [28]. Future studies will concentrate on defining specific lymphocyte and monocyte subpopulations and associated signaling and to better understand $\mathrm{B}$ and $\mathrm{T}$ cell interactions in prostate tumor regions compared to benign regions.

Rituximab was chosen given its efficacy and safety profile. Initially approved in 1997 for the treatment of relapsed or refractory B-cell Non-Hodgkin's Lymphoma (NHL), rituximab causes rapid depletion of circulating and tissue-based B-cells generally within the first three doses, with sustained depletion for up to 6-9 months after treatment [29]. Rituximab has subsequently been approved for several additional indications including chronic lymphocytic leukemia (CLL), rheumatoid arthritis, Wegener's granulomatosis and microscopic polyangiitis. Common adverse reactions observed in clinical trials of lymphoid malignancies were infusion reactions, fever, lymphopenia, neutropenia, chills, infection and asthenia ( $\geq 25 \%$ ) [30]. We noted four Grade 1 and 2 adverse events that were probably related to rituximab (infusion reaction and fatigue) occurring in three of the eight patients. Both infusion related reactions were able to be dose increased and complete the full cycle. This suggest a well-tolerated profile in the prostate cancer population.
The strengths of this study are the prospective design with rigorous, blinded assessment of B-cell density in tumor and adjacent tissue. Since the study started, two case reports have described treatment of metastatic PCa patients with rituximab. The first was a 66-year-old male who developed metastatic PCa; a lesion biopsy disclosed prominent $\mathrm{CD} 20+$ nests. He was treated with rituximab which resulted in a significant PSA decline [31]. The second was a 79-year-old metastatic PCa patient with a concurrent B-cell lymphoma. On treating his lymphoma with rituximab, he had a dramatic decline in PSA and his skeletal lesions showed signs of resolving [32]. To our knowledge, other than these reports, no other prospective studies of B-cell densities have been conducted.

This study adds to the rapidly evolving field of immunomodulating the tumor microenvironment of PCa. Other studies assessing are correlative retrospective tissue assessment $[24,25]$ or are evaluations of circulating lymphoid cells [33].

The current study is one of the few neoadjuvant immune trials to report results. Prior neoadjuvant studies either terminated or withdrew (NCT00577356/ NCT01197209) or have not published results. Gao et al. [28] demonstrated that neoadjuvant ipilimumab increased $\mathrm{CD} 4+$ and $\mathrm{CD} 8+$ cells within prostatectomy specimens, but did not mention effects on CD20+ cells.

Weaknesses include unknown impact on clinical outcomes, or impact of T-cell modulation. However, the primary outcome of the study was met, and the study design was not powered for secondary outcomes. Because of the small number of patients in this study it is hard to generalize our results, however this is the only prospective assessment of B-cell modulation in prostate cancer. Our method of lymphocyte annotation is not widely used, but we have published experience using this imaging quantification method for B cells [13]. An important difference between the animal models that served as the background work for the trial design was that they used castrated PCa mouse models, whereas this patient cohort did not receive androgen deprivation therapy. 
Recently, three studies showed that the presence of B cells in tumor regions in patients with metastatic melanoma or sarcoma who were treated with immune checkpoint blockade (ICB) immunotherapy were predictive of good prognosis [34-36]. In particular, B cells that were in tertiary lymphoid structures (TLS) which contain aggregates of multiple immune cell types, were present in responding patients. $\mathrm{B}$ cells, therefore, have both positive and negative roles in tumor immunology, and thus, it is critical to elucidate the precise tumor infiltrating $B$ cell and $T$ cell states, or types, and their interactions within TLSs not only for prognosis but also to tailor immunotherapy regimens and improve the anti-tumor response in prostate cancer.

\section{Conclusions}

Neoadjuvant rituximab was well-tolerated and decreased B-cell density within high risk PCa tumors compared to controls. Rituximab appeared to reduce the density of tumor-resident B-cells to levels comparable to adjacent normal tissue. Somewhat unexpectedly, there was a significant decrease in $\mathrm{CD} 3+\mathrm{T}$ cell density in prostate tumor regions of the rituximab-treated patients, demonstrating the essential interaction of these cell types in prostate cancer. These results provide evidence that rituximab can modify the immune microenvironment of the tumor.

\section{Supplementary information}

Supplementary information accompanies this paper at https://doi. org/10.1186/s12967-020-02370-4.

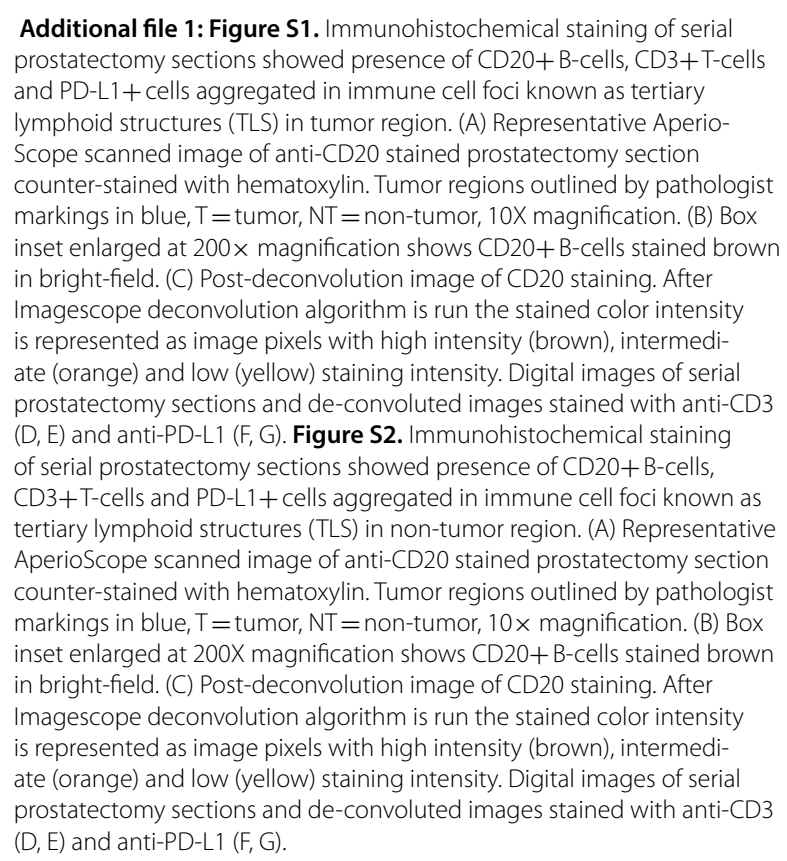

\section{Acknowledgements}

We thank the patients who participated in this study. We are deeply grateful to the Leo and Anne Albert Foundation for funding the Albert Summer Scholars: DN Burner, NE Basler and J Cunha. We wish to thank to Laarni Gapuz and Michael Rose of the UCSD Moores Cancer Center Tissue Technology Shared Resources for technical expertise and performance of immunohistochemical staining. We also wish to thank Abril Zuniga, Duy Tong and Catalina Arreola for their contributions to digital IHC image analysis and Keith Lander for proofreading.

\section{Authors' contributions}

Conception and design: CAMJ, CJK, MK, SS. Acquisition of data: CJK (recruited patients and performed prostatectomies), CAMJ (PI of laboratory for quantitative digital IHC), STR (SUO fellow), ML (SUO fellow), DNB (CJ), MM (CJ), EP (KM), AS (GU pathologist), MVE (IHC core facility director), NB (CJ), JC (CJ). Analysis and interpretation of data: KM, STR, JZ, EP, CAMJ, CJK. Drafting of the manuscript: STR, CAMJ. Critical revision of the manuscript for important intellectual content: CJK, JZ, DNB, MVE, KM, SH. Statistical analysis: KM, STR, JZ, EP. Obtaining funding: SH, CAMJ, CK, MK. All authors read and approved the final manuscript.

\section{Funding}

Genentech, Inc., South San Francisco, California, USA provided funding for the clinical trial but did not have any role in trial conception, trial design, data collection, data analysis and interpretation, or writing of the report. CK and CJ had full access to all the data in the study and had final responsibility to submit for publication.

\section{Availability of data and materials}

Individual participant data that underlie the results reported in this article, after de-identification (text, tables, figures, and appendices) will be available. The study protocol, statistical analysis, analytic code will be made available immediately after publication with no end date to researchers who provide a methodologically sound proposal. Proposals should be directed to camjamieson@health.ucsd.edu to gain access and data requestors will need to sign a data access agreement.

\section{Ethics approval and consent to participate}

This was a phase I open-label non-randomized single arm study of neoadjuvant rituximab in patients with high-risk PCa who were candidates for radical prostatectomy ("PROTUX" NCT01804712). The study was conducted in accordance with principles of the Declaration of Helsinki, in compliance with Good Clinical Practice (GCP), and approved by the University of California, San Diego institutional review board (IRB protocol \#121451). All patients signed informed consent form.

\section{Consent for publication}

No individual person's data or personal health information in any form is used, therefore, individual consents are not applicable for this manuscript.

\section{Competing interests}

CJ reports investigator-initiated project funding from Calibr, Inc., Astellas, Medivation, and Pfizer outside the submitted work. SH is a Member, Board of Directors, Abeona Therapeutics (ABEO), Member, Scientific Advisory Committee, Aptose Biosciences and has Equity ownership in Abeona Therapeutics, InhibRx and Aptose Biosciences all outside the submitted study. CK reports being on the Scientific advisory board and having stock ownership in Stratify genomics; Jansen Pharmaceuticals; research support and scientific advisory board, Dendreon Inc; scientific advisory board all activities were outside the submitted work. All other authors declare no competing interests related to this study.

\section{Author details}

${ }^{1}$ Department of Urology, UCSD Moores Cancer Center, University of California San Diego School of Medicine, 3855 Health Sciences Drive, Mail Code: 0987, La Jolla, CA 92093-0987, USA. ${ }^{2}$ Department of Pathology, University of California San Diego School of Medicine, La Jolla, CA, USA. ${ }^{3}$ Department of Pharmacology, University of California San Diego School of Medicine, La Jolla, CA, USA. ${ }^{4}$ Department of Pharmacology, University of California San Diego School of Medicine, La Jolla, CA, USA. ${ }^{5}$ Department of Medicine, University 
of California San Diego School of Medicine, La Jolla, CA, USA. ${ }^{6}$ Division of Biostatistics, Department of Family and Preventive Medicine, University of California San Diego School of Medicine, La Jolla, CA, USA. ${ }^{7}$ Department of Urology, University of Texas Health Science Center San Antonio, San Antonio, TX, USA. ${ }^{8}$ Biorepository and Tissue Technology Shared Resource at the University of California San Diego School of Medicine, La Jolla, CA, USA.

Received: 27 March 2020 Accepted: 12 May 2020

Published online: 28 May 2020

\section{References}

1. Hanahan D, Weinberg RA. Hallmarks of cancer: the next generation. Cell. 2011;144(5):646-74. https://doi.org/10.1016/J.CELL.2011.02.013.

2. Hanahan D, Coussens LM. Accessories to the crime: functions of cells recruited to the tumor microenvironment. Cancer Cell. 2012;21(3):309-22. https://doi.org/10.1016/J.CCR.2012.02.022

3. Hodi FS, O'Day SJ, McDermott DF, et al. Improved survival with ipilimumab in patients with metastatic melanoma. N Engl J Med. 2010;363(8):711-23. https://doi.org/10.1056/NEJMoa1003466.

4. Topalian SL, Hodi FS, Brahmer JR, et al. Safety, activity, and immune correlates of anti-PD-1 antibody in cancer. N Engl J Med. 2012;366(26):2443-54. https://doi.org/10.1056/NEJMoa1200690.

5. Kwon ED, Drake CG, Scher HI, et al. I pilimumab versus placebo after radiotherapy in patients with metastatic castration-resistant prostate cancer that had progressed after docetaxel chemotherapy (CA184-043): a multicentre, randomised, double-blind, phase 3 trial. Lancet Oncol. 2014;15(7):700-12. https://doi.org/10.1016/S1470-2045(14)70189-5.

6. Robert C, Long GV, Brady B, et al. Nivolumab in previously untreated melanoma without BRAF mutation. N Engl J Med. 2015;372(4):320-30. https:// doi.org/10.1056/NEJMoa1412082.

7. Rizvi NA, Mazières J, Planchard D, et al. Activity and safety of nivolumab, an anti-PD-1 immune checkpoint inhibitor, for patients with advanced, refractory squamous non-small-cell lung cancer (CheckMate 063): a phase 2, single-arm trial. Lancet Oncol. 2015;16(3):257-65. https://doi.org/10.1016/ S1470-2045(15)70054-9.

8. Subudhi SK, Aparicio A, Gao J, et al. Clonal expansion of CD8 T cells in the systemic circulation precedes development of ipilimumab-induced toxicities. Proc Natl Acad Sci. 2016;113(42):11919-24. https://doi.org/10.1073/ pnas.1611421113

9. Bellmunt J, de Wit R, Vaughn DJ, et al. Pembrolizumab as second-line therapy for advanced urothelial carcinoma. N Engl J Med. 2017;376(11):1015-26. https://doi.org/10.1056/NEJMoa1613683.

10. Strasner A, Karin M. Immune infiltration and prostate cancer. Front Oncol. 2015:5:128. https://doi.org/10.3389/fonc.2015.00128.

11. Ammirante M, Luo JL, Grivennikov S, Nedospasov S, Karin M. B-cell-derived lymphotoxin promotes castration-resistant prostate cancer. Nature. 2010;464(7286):302-5. https://doi.org/10.1038/nature08782.

12. Shalapour S, Font-Burgada J, Di Caro G, et al. Immunosuppressive plasma cells impede T-cell-dependent immunogenic chemotherapy. Nature. 2015;521(7550):94-8. https://doi.org/10.1038/nature14395

13. Woo JR, Liss MA, Muldong MT, et al. Tumor infiltrating B-cells are increased in prostate cancer tissue. J Transl Med. 2014;12(1):30. https://doi. org/10.1186/1479-5876-12-30.

14. Partin AW, Kattan MW, Subong ENP, et al. Combination of prostate-specific antigen, clinical stage, and Gleason score to predict pathological stage of localized prostate cancer. JAMA. 1997;277(18):1445. https://doi.org/10.1001/ jama.1997.03540420041027.

15. Bilusic M, Madan RA, Gulley JL. Immunotherapy of prostate cancer: facts and hopes. Clin Cancer Res. 2017;23(22):6764-70. https://doi.org/10.1158/10780432.CCR-17-0019.

16. Gajewski TF, Schreiber H, Fu Y-X. Innate and adaptive immune cells in the tumor microenvironment. Nat Immunol. 2013;14(10):1014-22. https://doi. org/10.1038/ni.2703.

17. Fujii T, Shimada K, Asai O, et al. Immunohistochemical analysis of inflammatory cells in benign and precancerous lesions and carcinoma of the prostate. Pathobiology. 2013;80(3):119-26. https://doi.org/10.1159/00034 2396.

18. Hussein M-RA, Al-Assiri M, Musalam AO. Phenotypic characterization of the infiltrating immune cells in normal prostate, benign nodular prostatic hyperplasia and prostatic adenocarcinoma. Exp Mol Pathol. 2009;86(2):10813. https://doi.org/10.1016/j.yexmp.2008.11.010.

19. Petitprez F, Fossati N, Vano Y, et al. PD-L1 expression and CD8+T-cell infiltrate are associated with clinical progression in patients with node-positive prostate cancer. Eur Urol Focus. 2019;5(2):192-6. https://doi.org/10.1016/j. euf.2017.05.013

20. Flammiger A, Bayer F, Cirugeda-Kühnert A, et al. Intratumoral T but not B lymphocytes are related to clinical outcome in prostate cancer. APMIS. 2012:120(11):901-8. https://doi.org/10.1111/j.1600-0463.2012.02924.x.

21. Kärjä V, Aaltomaa S, Lipponen P, Isotalo T, Talja M, Mokka R. Tumour-infiltrating lymphocytes: a prognostic factor of psa-free survival in patients with local prostate carcinoma treated by radical prostatectomy. Anticancer Res. 2005;25(6C):4435-8

22. Chen DS, Mellman I. Oncology meets immunology: the cancer-immunity cycle. Immunity. 2013;39(1):1-10. https://doi.org/10.1016/J.IMMUN 1.2013.07.012.

23. Schietinger A, Greenberg PD. Tolerance and exhaustion: defining mechanisms of T cell dysfunction. Trends Immunol. 2014;35(2):51-60. https://doi. org/10.1016/J.IT.2013.10.001.

24. Davidsson S, Ohlson A-L, Andersson S-O, et al. CD4 helper T cells, CD8 cytotoxic T cells and FOXP3 + regulatory T cells with respect to lethal prostate cancer. Mod Pathol. 2013;26(3):448-55. https://doi.org/10.1038/modpa thol.2012.164.

25. García-Hernández MDLL, Uribe-Uribe NO, Espinosa-González R, Kast WM, Khader SA, Rangel-Moreno J. A unique cellular and molecular microenvironment is present in tertiary lymphoid organs of patients with spontaneous prostate cancer regression. Front Immunol. 2017:8:563. https:/doi. org/10.3389/fimmu.2017.00563.

26. Linsley PS, Greenbaum CJ, Rosasco M, Presnell S, Herold KC, Dufort MJ. Elevated T cell levels in peripheral blood predict poor clinical response following rituximab treatment in new-onset type 1 diabetes. Genes Immun. 2018. https://doi.org/10.1038/s41435-018-0032-1.

27. Battella S, Cox MC, La Scaleia R, et al. Peripheral blood T cell alterations in newly diagnosed diffuse large B cell lymphoma patients and their longterm dynamics upon rituximab-based chemoimmunotherapy. Cancer Immunol Immunother. 2017;66(10):1295-306. https://doi.org/10.1007/ s00262-017-2026-7.

28. Gao J, Ward JF, Pettaway CA, et al. VISTA is an inhibitory immune checkpoint that is increased after ipilimumab therapy in patients with prostate cancer. Nat Med. 2017;23(5):551-5. https://doi.org/10.1038/nm.4308.

29. Anderson K, Bates M, Slaughenhoupt B, et al. Expression of human B cellassociated antigens on leukemias and lymphomas: a model of human B cell differentiation. Blood. 1997;63(6):1424-33.

30. FDA. Rituximab (Rituxan) Product Information. FDA-Open access Doc. 1997.

31. Dalgleish A, Featherstone P, Vlassov V, Rogosnitzky M. Rituximab for treating CD20+ prostate cancer with generalized lymphadenopathy: a case report and review of the literature. Investig New Drugs. 2014;32(5):1048-52. https //doi.org/10.1007/s10637-014-0063-Z.

32. Bindal P, Jalil SA, Holle LM, Clement JM. Potential role of rituximab in metastatic castrate-resistant prostate cancer. J Oncol Pharm Pract. 2018. https:// doi.org/10.1177/1078155218790338.

33. Fong $L$, Carroll $P$, Weinberg $V$, et al. Activated lymphocyte recruitment into the tumor microenvironment following preoperative sipuleucel-T for localized prostate cancer. J Natl Cancer Inst. 2014. https://doi.org/10.1093/jnci/ dju268

34. Helmink BA, Reddy SM, Gao J, et al. B cells and tertiary lymphoid structures promote immunotherapy response. Nature. 2020;577(7791):549-55. https:// doi.org/10.1038/s41586-019-1922-8.

35. Petitprez F, de Reyniès A, Keung EZ, et al. B cells are associated with survival and immunotherapy response in sarcoma. Nature. 2020;577(7791):556-60. https://doi.org/10.1038/s41586-019-1906-8.

36. Cabrita R, Lauss M, Sanna A, et al. Tertiary lymphoid structures improve immunotherapy and survival in melanoma. Nature. 2020;577:561-5. https:// doi.org/10.1038/s41586-019-1914-8.

\section{Publisher's Note}

Springer Nature remains neutral with regard to jurisdictional claims in published maps and institutional affiliations. 